Apuntes Universitarios, 2020: 10(4), octubre-diciembre

ISSN: 2304-0335 DOI:https://doi.org/10.17162/au.v10i4.516

\title{
Identificación de indicadores de productividad de recursos humanos en organizaciones ejecutivas y análisis de su situación
}

\section{Identifying Human Resources Productivity Indicators in Executive Organizations and Analyzing their Situation}

\author{
Ali Shahabi Nasab ${ }^{1 a}$, Alireza Manzari Tavakoli ${ }^{2}$, Sanjar Salajegheh $^{3}$, \\ y Ayob Sheykhi ${ }^{4}$ \\ Islamic Azad University, Kerman, $\operatorname{Iran}^{123}$ \\ Shahid Bahonar University of Kerman, $\operatorname{Iran}^{4}$ \\ (iD) Orcid ID: https://orcid.org/0000-0003-2387-4037 \\ Orcid ID: https://orcid.org/0000-0003-4271-782X ${ }^{2}$ \\ Orcid ID: https://orcid.org/0000-0002-3412-67313 \\ Orcid ID: https://orcid.org/0000-0002-3731-6012
}

Recibido: 19 de enero de 2020

Aceptado: 15 de julio de 2020

\begin{abstract}
Resumen
Este estudio tuvo como objetivo identificar los indicadores de productividad de los recursos humanos en las organizaciones ejecutivas de Kohgiluyeh y la provincia de Boyer-Ahmad y analizar su situación. Esta investigación se aplica en propósito, de naturaleza descriptivacorrelacional, mediante un método de investigación por encuesta. La población estadística estuvo compuesta por todos los empleados de las organizaciones ejecutivas de Kohgiluyeh y Boyer-Ahmad (8.089 individuos), que según la fórmula de Cochran, el tamaño de la muestra se estimó en 366 individuos y la selección se basó en un método de agrupamiento aleatorio. Para recopilar datos, se utilizó el cuestionario de productividad de los empleados de Goldsmith (1980). Los expertos confirmaron la validez de la cara y el contenido del cuestionario, y el coeficiente alfa de Cronbach fue superior a 0.7, lo que muestra la consistencia entre ítems y la confirmación de la confiabilidad. Para examinar los datos, se realizó un análisis factorial exploratorio utilizando LISREL. Según los resultados, los datos obtenidos se ajustaron adecuadamente con la estructura de factores del indicador de productividad de recursos humanos y los ítems de este indicador fueron consistentes con la construcción de la infraestructura. Los resultados de las subescalas mostraron que los indicadores de motivación (89.34), habilidad (87.15) y credibilidad (80.05) estaban respectivamente en el primer al tercer lugar en términos de nivel de recursos humanos de las organizaciones ejecutivas de Kohgiluyeh y Boyer-Ahmad. En conclusión, se sugiere enfatizar la importancia de los recursos humanos competentes y eficientes para mejorar la productividad organizacional y motivar a los recursos humanos que trabajan en las organizaciones ejecutivas de Kohgiluyeh y Boyer-Ahmad para trabajar más y ser más eficientes utilizando incentivos materiales y espirituales.
\end{abstract}

Palabras clave: Productividad, recursos humanos, organizaciones ejecutivas, administración, gestión administrativa 


\section{Abstract}

This study aimed to identify the indicators of human resource productivity in the executive organizations of Kohgiluyeh and the province of Boyer-Ahmad and to analyze their situation. This research is applied on purpose, descriptive-correlational in nature, using a survey research method. The statistical population was made up of all the employees of the executive organizations of Kohgiluyeh and Boyer-Ahmad (8,089 individuals), which according to the Cochran formula, the sample size was estimated at 366 individuals and the selection was based on a method of random grouping. To collect data, Goldsmith's (1980) employee productivity questionnaire was used. The experts confirmed the validity of the face and the content of the questionnaire, and the Cronbach's alpha coefficient was higher than 0.7, which shows the consistency between items and the confirmation of reliability. To examine the data, an exploratory factor analysis was performed using LISREL. According to the results, the data obtained was adequately adjusted with the factor structure of the indicator of productivity of human resources and the items of this indicator were consistent with the construction of the infrastructure. The results of the subscales showed that the indicators of motivation (89.34), ability (87.15) and credibility (80.05) were respectively in first to third place in terms of level of human resources of the executive organizations of Kohgiluyeh and Boyer-Ahmad. In conclusion, it is suggested to emphasize the importance of competent and efficient human resources to improve organizational productivity and motivate human resources working in the executive organizations of Kohgiluyeh and Boyer-Ahmad to work more and be more efficient using material and spiritual incentives.

Keywords: Productivity, Human Resources, Executive Organizations, Kohgiluyeh and BoyerAhmad.

\section{Introduction}

The concept of productivity should be considered in the organizations and their performance success. Organizational productivity, and in more specialized terms, the human resources productivity in organizations, is one of the possible consequences of considering the indicators and human resources. Productivity is a culture and a rational approach to work and life that aims to make activities smarter for a better and excellent life (Boselie et al., 2020).

If an organization can achieve its goals of customer satisfaction, it will be an effective organization. However, if the organization achieves the same goal by decreasing the number of its employees, it will be more efficient than before. Many scholars of the management and economics argue that empowering human resources as the most effective element in the realization of efforts is considered the most profitable and important element of development among different types of investments that are made to improve productivity and finally economic and social development (Caliskan, 2010).

The main goal of a company is always to earn money or in other words profitability. The company's profitability almost depends on its long-term productivity. Profitability shows the company's current financial situation, and productivity reflects the company's future position. A company can only continue its profitability if it does not ignore the productivity (Chew \& Basu, 2005).

To increase productivity in the organization, several conditions should be provided that human resources are the most important factor. The emerged human resources to do the duties 
are a significant factor in productivity. Human resource is one of the most valuable resources of any organization and has been a major factor in the development of many countries for a long time. Human resources can be efficient and capable if they are able to make an efficient, profitable and useful organization to the society, and in general, make the country prosperous and independent (Cho et al., 2017).

\section{Research background}

In a study, the influential factors in increasing organizational productivity based on human resources were investigated. The researchers finally found that considering the basic needs of employees is the most important factor in promoting organizational productivity. It was further determined that the participation of human resources in decision-making is of secondary importance of developing organizational productivity. Eventually, this study showed that leadership style is also one of the effective components (Collins, 2007).

In his research, he presented and proposed effective solutions to increase the productivity of human resources in organizations and finally argued that strategies such as paying attention to the increasing participation of employees, proper selection of employees and staff training, type and style of leadership o managers, review and reform the organizational structure (pay more attention to the development and regulating clear job descriptions for organizational positions of all employees, considering the conditions of job promotion, documenting affairs and regulating work procedures) and ultimately, improving the employee compensation system are the most important influential factors in human resources productivity of organizations (Delery \& Doty, 1996).

In his research, he examined the influential indicators on the productivity of human resources and organizational productivity. The researcher argued that the ability or job readiness of human resources, organizational support of human resources (encouraging and motivating workforce by managers and agents outside the organization), motivation and willingness of human resources to accept the profession and work field in the organization ( the relevance of the field of expertise to the field of work, the importance of the employees' work filed in promoting the goals of the organization), informal feedback on the workforce performance during their working hours, assessing the validity of human resources decisions in terms of law and norms by managers and finally environmental adaptation are the most important factors affecting human resource productivity, which enhance organizational performance and finally improve organizational productivity (Farhangi et al., 2014).

In their research, they identified and prioritized the influential indicators on human resource productivity in organizations. Organizational culture has consisted of components such as innovation, risk-taking, considering the details, considering the achievements, paying attention to the role of members of the organization and emphasize on the organizational 
progress and sustainability. Environmental conditions are in the second rank of relation to the organizations' human resource productivity, which include five components of adequate facilities, quiet physical environment, adequate ventilation systems, modernity of physical space, and the size and extent of physical space (Gholamzadeh \& Jalali, 2012).

In their research entitled "Analysis of Influential Internal and External Organizational Factors on Human Resource Productivity" showed that factors of management styles and compensation systems (reward systems) have the most impact on human resource productivity in organizations. Therefore, among three managerial factors affecting the human resource productivity, planning and activities to attract and encourage productive employees have the greatest role to improve productivity, and delegation of providing open and transparent communication between managers and employees has the least role (Lado \& Wilson, 2018).

In their research, they explored the effective strategies for improving human resource productivity. Data analysis showed that strategies such as creating a positive attitude in employees about productivity issues, designing impartial models to evaluate performance and reward in the organization, implementing participatory management in the organization, providing more appropriate and practical training courses on productivity, and paying attention to ergonomics issues in the organization are effective in improving human resource productivity in organizations and ultimately will be effective in the performance of organization (Macleod et al., 2014).

In their research, they prioritized organizational indicators and components that are effective in developing human resource productivity in public and private organizations. The researchers found that there is a significant relationship between organizational factors and human resource productivity. There is a significant relationship between the impressive factors on the quality of working life and improving human resource productivity. There is also a significant relationship between human resource job-related factors and improving human resource productivity, and finally there is a significant relationship between variables such as feedback, the job, performance evaluation and staff needs with promoting human resource productivity (Ordonez de Pablos \& Lytras, 2008).

They determined the human resource indicators and their roles in promoting organizational performance and productivity. They found that human resource indicators affect the various dimensions of organization performance, such as productivity, the amount of movement and transfer of human resources and corporate financial performance. Considering the effect of HRMP on the performance of the organization as the main way in this area is one of the main components in studying organizational productivity (Tzafrir, 2015).

\section{Research questions}

Question 1: What are the indicators of human resource productivity in executive organizations of Kohgiluyeh and Boyer-Ahmad Province? 
Question 2: What is the status of human resource productivity indicators in Kohgiluyeh and Boyer-Ahmad executive organizations?

\section{Methodology}

This research was applied in terms of purpose and in nature was descriptivecorrelational and it had a survey research method. The statistical population included all the employees of Kohgiluyeh and Boyer-Ahmad executive organizations (8.089 individuals). According to Cochran formula, the sample size was estimated to be 366 people and was selected by random clustering method. For collecting data, Goldsmith (1.980) employee productivity questionnaire was used. This questionnaire has 21 questions and 7 components of ability (knowledge and skills), clarity (understanding or imagining the role), assistance (organizational support), evaluation (training and approach to performance), credibility, motivation (stimulation and tendency) and environment (environmental fit) are measured. Scoring the questionnaire is based on a 5-degree scale on the Likert scale, so that for very low options (1point), low ( 2 points), to some extent ( 3 points), high (4 points) and very high (5 points) are considered. Each three questions are devoted to measuring one of the components such as questions 1-2-3 (ability, knowledge and skills), 4-5-6 (clarity), 7-8-9 (organizational assistance and support), 10-11-12 (evaluation), 13-14-15 (credibility), 16-17-18 (motivation) and 19-2021 (environment and environmental fit) are measured. The range of scores of this questionnaire is between 21 and 105. (Tzafrir, 2005) has reported the validity and reliability of this scale using internal consistency validity as 0.69 and 0.80 , respectively. Furthermore, the validity and reliability of the questionnaire in the research (Wattanasupachoke, 2009) using content validity and retesting on 400 samples was obtained as 0.86 and 0.78 , respectively. In order to analyze the data, exploratory factor analysis using LISREL was applied.

\section{Results}

In relation to the two previous research questions above, the results are presented according to those questions:

Question 1: What are the indicators of human resource productivity in executive organizations of Kohgiluyeh and Boyer-Ahmad Province? 
Table 1

Kaiser-Meyer-Olkin measure of sampling adequacy (KMO) test and Bartlett's test of sphericity of human resource productivity indicators

\begin{tabular}{llllc}
\hline Variable & KMO & $\begin{array}{l}\text { Bartlett's test of } \\
\text { sphericity }\end{array}$ & Df & Sig \\
\hline $\begin{array}{l}\text { Human resource } \\
\text { productivity }\end{array}$ & 0.632 & 1544.69 & 365 & $\mathrm{P}<0.05$ \\
\hline
\end{tabular}

The results of Table 1 show that KMO for the variable of human resource productivity is 0.632 , which indicates the adequacy of the selected sample. Furthermore, Bartlett's test of sphericity (1544.69) is significant at $\mathrm{p}<0.05$ level and shows that the data correlation in the community is not zero. For this reason, it is determined that performing factor analysis to identify human resource productivity indicators is permissible and appropriate.

Table 2

Exploratory factor analysis of subscales and indicators of human resource productivity in executive organizations

\begin{tabular}{|c|c|c|c|}
\hline \multirow[t]{2}{*}{ Components } & \multicolumn{3}{|l|}{ Statistic } \\
\hline & Eigenvalues & $R^{2}$ & Cumulative variance \\
\hline Motivation (stimulation,tendency) & 1.67 & 27.51 & 27.51 \\
\hline Ability (knowledge and skills) & 2.35 & 21.19 & 21.19 \\
\hline Credibility & 1.93 & 18.37 & 18.37 \\
\hline $\begin{array}{l}\text { Clarity (understanding or imaging } \\
\text { the role) }\end{array}$ & 3.55 & 8.53 & 8.53 \\
\hline Environment (environmental fit) & 2.31 & 6.50 & 6.50 \\
\hline $\begin{array}{l}\text { Evaluation (training and } \\
\text { performance impact) }\end{array}$ & 2.90 & 3.45 & 3.45 \\
\hline (organizational & 2.43 & 2.61 & 2.61 \\
\hline
\end{tabular}

In exploratory factor analysis of subscales and human resource productivity indicators in Kohgiluyeh and Boyer-Ahmad executive organizations, using Varimax rotation, 7 factors were obtained with eigenvalues higher than one and factor loading more than 0.35 , and they were identified as subscales and indicators of human resource productivity in the executive organizations of Kogiluyeh and Boyer-Ahmad.

According to the results of Table 2, it can be seen that among the indicators of human resource productivity, motivation indicators (27/51), ability: knowledge and skills (21.91) and creditability (18.37) explain $67.07 \%$ of related variance to the human resource productivity indicator. After these indicators, the indicators of clarity: understanding or imagining the role 
(8.53) and the environment: environmental fit (6.50) are placed, which together explain $15.03 \%$ of the total variance related to the human resource productivity indicator. Finally, evaluation indicators: training and performance impact (3.45) and assistance: organizational support (2.61), also have a $0.6 \%$ determination of the variance of the human resource productivity indicator.

Based on the results of factor analysis, motivation indicators, ability: knowledge and skills, credibility, clarity: understanding or imagining the role, environment: environmental fit, evaluation: training and approach to performance and assistance: organizational support are extracted and identified as indicators of human resource productivity in the executive organizations of Kohgiluyeh and Boyer-Ahmad.

\section{Table 3}

Confirmatory factor analysis of human resource productivity indicators in Kohgiluyeh and BoyerAhmad executive organizations

\begin{tabular}{|c|c|c|c|c|}
\hline Components & $\mathrm{CR}$ & AVE & t-value & Factor loading \\
\hline Motivation (tendency) & 0.85 & 0.77 & 16.37 & 0.92 \\
\hline Ability (knowledge and skills) & 0.80 & 0.72 & 15.43 & 0.87 \\
\hline Credibility & 0.63 & 0.55 & 13.69 & 0.70 \\
\hline $\begin{array}{l}\text { Clarity (understanding or imaging } \\
\text { the role) }\end{array}$ & 0.56 & 0.48 & 11.45 & 0.63 \\
\hline Environment (environmental fit) & 0.74 & 0.66 & 15.82 & 0.81 \\
\hline $\begin{array}{l}\text { Evaluation (training and approach to } \\
\text { performance) }\end{array}$ & 0.54 & 0.46 & 10.94 & 0.51 \\
\hline Assistance (organizational support) & 0.71 & 0.63 & 14.27 & 0.75 \\
\hline
\end{tabular}

The results of Table 3 regarding the confirmatory factor analysis of human resource productivity indicators in Kohhgilouyeh and Boyer-Ahmad executive organizations suggest that all analyzed human resource productivity indicators have a factor loading more than 0.35 , therefore they are confirmed as the extracted factors and indicators of human resource productivity. Finally, according to the values of CR and average variance extracted (AVE) of human resource productivity indicators in Kohgiluyeh and Boyer-Ahmad executive organizations, it is determined that the mentioned model the extracted indicators can be considered as a standard and acceptable model for identifying human resource productivity indicators (Figure 1). 


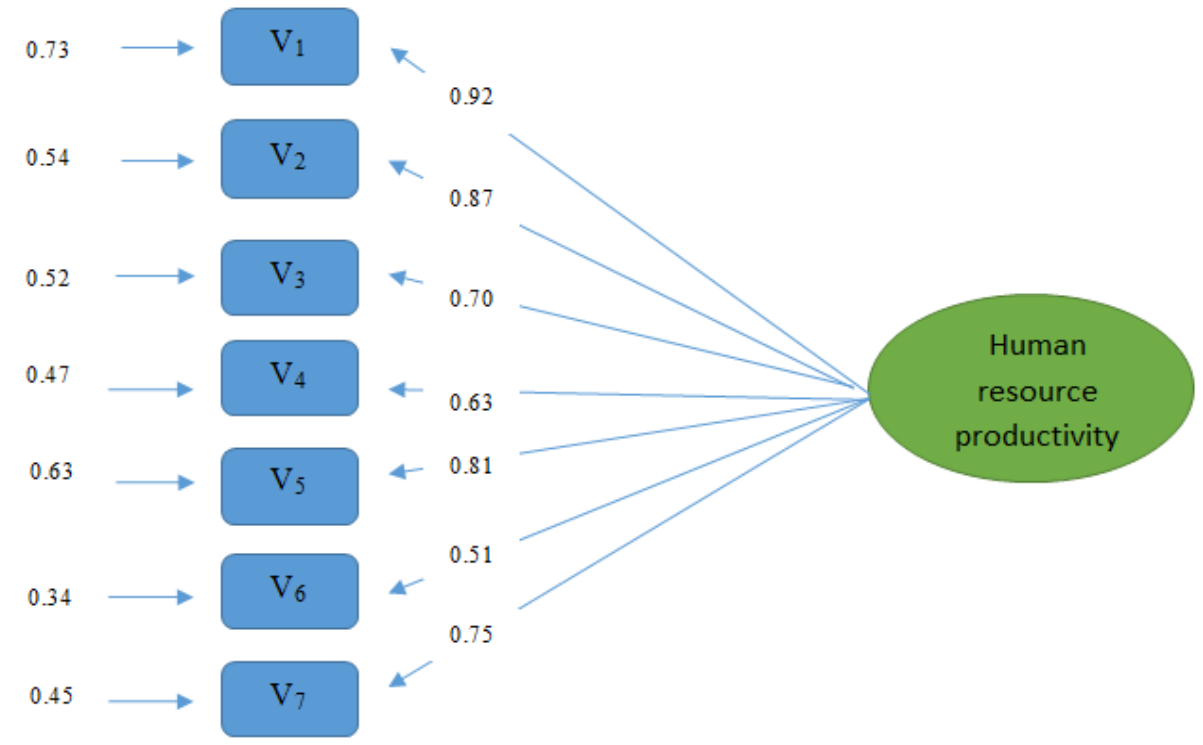

Figure 1. Confirmatory factor analysis of human resource productivity indicators

\section{Table 4}

The results of exploratory factor analysis with Varimax rotation of human resource productivity indicators

\begin{tabular}{ll}
\hline Indicators & Statistic \\
\hline Motivation (tendency) & 0.35 \\
Ability (knowledge and skills) & 0.79 \\
Credibility & 0.61 \\
Clarity (understanding or imaging the role) & 0.68 \\
Environment (environmental fit) & 0.77 \\
Evaluation (training and approach to performance) & 0.91 \\
Assistance (organizational support) & 0.54 \\
\hline
\end{tabular}

After performing exploratory factor analysis with Varimax rotation, human resource productivity indicators in Kohgilouyeh and Boyer-Ahmad executive organizations, all the items and extracted factors remained unchanged. The performed analysis and the repetition of 7 factors in it suggest the appropriate validity of the factor analysis (Table 4). 
Table 5

Goodness of fit characteristics for human resource productivity indicators in executive organizations

\begin{tabular}{llllllll}
\hline Characteristic & $\begin{array}{l}\text { Motivatio } \\
\text { n } \\
\text { (stimulati } \\
\text { on, } \\
\text { tendency) }\end{array}$ & $\begin{array}{l}\text { Ability } \\
\text { (knowledge } \\
\text { and skills) }\end{array}$ & Credibility & $\begin{array}{l}\text { Clarity } \\
\text { (understanding } \\
\text { or imagining } \\
\text { the role }\end{array}$ & $\begin{array}{l}\text { Environment } \\
\text { (environmental } \\
\text { fit) }\end{array}$ & $\begin{array}{l}\text { Evaluation } \\
\text { (training and } \\
\text { approach to } \\
\text { performance }\end{array}$ & $\begin{array}{l}\text { Assistance } \\
\text { (organization }\end{array}$ \\
\hline $\begin{array}{l}\text { The ratio of } \\
\text { chi-square to } \\
\text { the freedom } \\
\text { degree }\end{array}$ & & 1.90 & 2.25 & 2.31 & 1.96 & 2.14 & 1.41 \\
$\begin{array}{l}\text { Root mean } \\
\text { square residual } \\
\text { (RMR) }\end{array}$ & & & & & & & \\
$\begin{array}{l}\text { Goodness of } \\
\text { fit index (GFI) }\end{array}$ & 0.063 & 0.069 & 0.051 & 0.054 & 0.059 & 0.048 & 0.065 \\
$\begin{array}{l}\text { Adjusted } \\
\text { goodness of fit } \\
\text { index (AGFI) }\end{array}$ & 0.77 & 0.69 & 0.94 & 0.82 & 0.91 & 0.97 & 0.87 \\
\end{tabular}

Table 5 shows that all fitness characteristics for human resource productivity indicators in Kohgilouyeh and Boyer-Ahmad executive organizations are at an acceptable level. In other words, the data of the factor structure of human resource productivity indicator have an appropriate fitting, and the items of this index are aligned with the infrastructural construct.

\section{Table 6}

Cronbach's Alpha of the subscales of the human resource productivity components

\begin{tabular}{ll}
\hline Indicators & Cronbach's alpha \\
\hline Motivation (stimulation, tendency) & 0.67 \\
Ability (knowledge and skills) & 0.79 \\
Credibility & 0.56 \\
Clarity (understanding or imaging the role) & 0.73 \\
Environment (environmental fit) & 0.61 \\
Evaluation (training and approach to performance) & 0.57 \\
Assistance (organizational support) & 0.92 \\
\hline Total alpha & 0.83
\end{tabular}

With regard to Table 6, the alpha values for subscales and components of the human resource productivity indicator in Kohgiluyeh and Boyer-Ahmad executive organizations are between 0.56 and 0.92 . Cronbach's alpha for the human resource productivity indicator was 0.83. This amount indicates the appropriate internal consistency of the subscales and 
components of the human resource productivity indicator.

Question 2: What is the status of human resource productivity indicators in Kohgiluyeh and Boyer-Ahmad executive organizations?

\section{Table 7}

The status of human resource productivity indicators in Kohgiluyeh and Boyer-Ahmad executive organizations

\begin{tabular}{|c|c|c|c|c|}
\hline Row & Sub-indicator & Frequency & Percentage & Index range \\
\hline 1 & $\begin{array}{l}\text { Motivation } \\
\text { (stimulation, } \\
\text { tendency) }\end{array}$ & 327 & 89.34 & $0.114-0.597$ \\
\hline 2 & $\begin{array}{l}\text { Ability } \\
\text { (knowledge and } \\
\text { skills) }\end{array}$ & 319 & 87.15 & 0.493-0.944 \\
\hline 3 & Credibility & 293 & 80.05 & $0.116-0.563$ \\
\hline 4 & $\begin{array}{l}\text { Clarity } \\
\text { (understanding or } \\
\text { imaging the role) }\end{array}$ & 261 & 71.31 & $0.394-0.768$ \\
\hline 5 & $\begin{array}{l}\text { Environment } \\
\text { (environmental } \\
\text { fit) }\end{array}$ & 195 & 53.27 & $0.473-0.921$ \\
\hline 6 & $\begin{array}{l}\text { Evaluation } \\
\text { (training and } \\
\text { approach } \\
\text { performance) }\end{array}$ & 173 & 47.26 & $0.361-0.564$ \\
\hline 7 & $\begin{array}{l}\text { Assistance } \\
\text { (organizational } \\
\text { support) }\end{array}$ & 149 & 40.71 & $0.537-0.755$ \\
\hline
\end{tabular}

The results of the subscales status of the human resource productivity indicators in the Kohgiluyeh and Boyer-Ahmad executive organizations indicate that the indicators of motivation (89/34), ability (87/15), credibility (80.05), clarity (71.31), environment (53/27), evaluation (47/26) and assistance (40.71) are respectively placed based on their level and amount in the first places to the seventh in human resources of Kohgiluyeh and Boyer-Ahmad executive organizations (Table 7).

\section{Discussion}

According to the results of factor analysis, ultimately, indicators of motivation, ability: knowledge and skills, credibility, clarity: understanding or imagining the role, environment: 
environmental fit, evaluation: training and approach to performance and assistance: organizational support, are extracted as indicators of human resource productivity in the Kohgiluyeh and Boyer-Ahmad executive organizations. Among the indicators human resource productivity, indicators of motivation: stimulation or tendency, ability: knowledge and skills and credibility have been identified as the main indicators of human resource productivity the most important indicators in measuring human resource productivity. Indicators of clarity: understanding or imagining the role and environment: Environmental fitness, are also known as sub-indicators and indicators that are of medium importance for measuring human productivity. Finally, indicators of evaluation: training and approach to performance and assistance: Organizational support, have also been recognized as indicators that are of least importance in measuring the human resource productivity.

In analyzing the importance of human resource development indicators, he argued that a large number of environmental and organizational changes have also helped to enhance human resource planning and management of employees affairs and human resources. With a resource-based view of the organization, we find that resources are only valuable to us when they grow efficiently and allow us to invest in opportunities and deal with threats (Ya-Fen \& Tzai-Zang, 2009). Therefore, the organization human capital creates value by cooperating in decreasing costs or improving services and products for customers. On the other hand, Collis and Montgomery believe that (in a strategic management environment) the importance of human capital depends on the level of creating competitiveness for the company. From an economic view, exchange theory states that an organization achieves competitive advantages when it has resources that are specific to the organization itself, so that none of the competitors can copy these resources. Consequently, the incomparable nature of human capital of any organization makes organizations to use and invest their organizational resources in the field of management (Maghsoudpour, 2002). This will reduce the risk and investment in the potentials of the organization's productivity and manufacturing. By combining two factors of uniqueness and strategic value of human capital, a matrix is formed that provides a conceptual framework for categorizing different types of human capital in the organization and also managing them for greater utilization in the organization (Easterly \& Levine, 2001). In fact, this framework states that for managing different types of human knowledge and capital in the organization, we need different systems in human resource management, so that using a single system in human resource management will be followed by reducing productivity in the organization. It should be noted again that the meaning of human capital in this model is the knowledge of skills and information of the organization human resources (King \& Levine, 2019). 


\section{Conclusion}

The results of the status of the human capital productivity indicators in the Kohgiluyeh and Boyer-Ahmad executive organizations indicate that these indicators are desirable among the human resources in Kohgiluyeh and Boyer-Ahmad executive organizations. Resources are valuable to us only when they are efficient and enable investment in opportunities and equip organizations and human resources to deal with threats. So in this view, the organization human capital creates value by cooperating in reducing costs or improving services and products for customers. On the other hand, Collis and Montgomery believe (in a strategic management environment) that the importance of human capital depends on the level of creating competitiveness for the company. From an economic point of view, exchange theory states that an organization gains competitive advantage when it has resources specific to itself, so that none of the competitors can copy these resources. Therefore, the incomparable nature of human capital of any organization causes organizations to use and invest their organizational resources in the fields of management. This will reduce the risk and investment in the possible potentials of the organization's productivity and manufacturing. By combining two factors of uniqueness and strategic value of human capital, a matrix is formed that provides a conceptual framework for categorizing the different types of human capital in the organization and managing them for greater utilization in the organization. In fact, this framework emphasizes that for management of different types of human knowledge and capital in the organization, we need different systems in human resource management, so that using a single system in human resource management will be accompanied with reducing of productivity in the organization. It is necessary to note that the meaning of human capital in this model is the knowledge of skills and information of the human resources of the organization.

\section{References}

Boselie P., Paauwe J. \& Jansen P. (2020), Human resource management and performance: Lessons from the Netherlands, International Journal of Human Resource Management, 12(7): 1107-1125.

Caliskan, E. (2010). The impact of strategic human resource management on organizational performance. Journal of Naval Science and Engineering, 6(2): 100-116.

Chew, K. \& Basu, S. (2005). The effects of culture and HRM practices on firm performance. Empirical evidence from Singapore, International Journal of Manpower, 26(6): 560-81.

Cho S., Woods R., Jang S. \& Erdem M. (2017), Measuring the impact of human resource management practices on hospitality firms' performances. Hospitality Management, 12(5): 262-277.

Collins, A. (2007), Human resources: A hidden advantage? International Journal of 
Contemporary Hospitality Management, 19(1): 78-84.

Delery, J. \& Doty, D. (1996). Modes of theorizing in strategic human resource management:

Tests of university contingency and configurational performance predictions. Academy of Management Journal, 39(6): 802-835.

Easterly, W. \& Levine, R. (2001), What Have we Learned from a Decade of Empirical Research on Growth? It's Not Factor Accumulation: Stylized Facts and Growth Models, World Bank Econ Rev, 15(2): 177-219.

Farhangi, A., Soltanifar, M., Mahaki A. \& Danaei A. (2014). The introduction of an appraisal system's performance based on a strategic map (Case Study: Hamshahri newspaper), Journal of public administration, 4(5): 175-200.

Gholamzadeh, D. \& Jalali, S. (2012), Human resources strategy formulation by strategic reference points theory (Case Study: RPK Company), Journal of public administration, 10(4): 137-152. (In Persian)

King, R. \& Levine, R. (2019), "Capital Fundamentalism, Economic Development, and Economic Growth", Carnegie-Rochester Conference Series on Public Policy, 40(2): 259-292.

Lado A. \& Wilson M. (2018), Human resource systems and sustained competitive advantage: A competency-based perspective, Academy of Management Journal, 19(4): 699-727.

Macleod, M., Bowden R., Bevan, N. \& Curson I. (2014), The music performance measurement method, Behavior and Information Technology, 16(2): 279-293.

Maghsoudpour, R. (2002), Designing an effective training evaluation process. Journal Of Eurpean Industrial Training, 16(5): 56-70.

Ordonez de Pablos, P. \& Lytras, M. (2008), Competencies and human resource management: Implications for Organizational Competitive Advantage, Journal of Knowledge Management, 12(6): 48-55.

Tzafrir, S. (2005), The relationship between trust, HRM practices and firm performance, International Journal of Human Resource Management, 16(9):1600-1622.

Tzafrir, S. (2015). A universalistic perspective for explaining the relationship between HRM practices and firm performance at different points in time. Journal of Managerial Psychology, 21(2): 109-130.

Wattanasupachoke T. (2009), Strategic human resource management and organizational performance: A study of Thai Enterprises. Journal of Global Business Issues, 3(2):139148.

Ya-Fen T. \& Tzai-Zang L. (2009), Comparing appropriate decision support of human resource practices on organizational performance with DEA/AHP model, Expert Systems with Applications, 36(1): 6548-6558. 